\title{
First trimester serum vitamin D, hs-CRP and second trimester uterine artery diastolic notching in predicting gestational hypertension and preeclampsia
}

\author{
Renu Arora ${ }^{1}$, Sueba Salmani ${ }^{1}$, Rekha Bharti ${ }^{1 *}$, B. C. Kabi ${ }^{2}$, Anjali Dabral ${ }^{1}$ \\ ${ }^{1}$ Department of Obstetrics and Gynecology, Vardhman Mahavir Medical College and Safdarjung Hospital, Delhi, India \\ ${ }^{2}$ Department of Biochemistry, Vardhman Mahavir Medical College and Safdarjung Hospital, Delhi, India
}

Received: 02August 2019

Revised: 18 October 2019

Accepted: 06 November 2019

\author{
*Correspondence: \\ Dr. Rekha Bharti, \\ E-mail: rekhabharti@gmail.com
}

Copyright: $\odot$ the author(s), publisher and licensee Medip Academy. This is an open-access article distributed under the terms of the Creative Commons Attribution Non-Commercial License, which permits unrestricted non-commercial use, distribution, and reproduction in any medium, provided the original work is properly cited.

\begin{abstract}
Background: Gestational hypertension and preeclampsia is one of the leading causes of maternal and fetal morbidity and mortality. The objective of this study was to study prediction of gestational hypertension/preeclampsia by using first trimester serum vitamin D and hs-CRP and second trimester uterine artery diastolic notching.

Methods: It was an observational study conducted in the departments of obstetrics and gynaecology, clinical biochemistry and radiology, Vardhman Mahavir Medical College and Safdarjung Hospital, New Delhi, India. All pregnant women with 11 to 14 weeks gestational age attending antenatal clinic between October 2012 and June 2013 were enrolled in the study. A detailed history including history of the duration of sun exposure was taken and a general physical examination including obstetrical examination was done at every visit. Serum sample were taken for hs-CRP and vitamin-D levels at 11-14 weeks. Uterine artery colour doppler study was done between 22-24 weeks for uterine artery diastolic notching. The main outcome measures were development of gestational hypertension/ preeclampsia/ eclampsia.

Results: The mean vitamin D levels were significantly lower and mean hs-CRP levels were significantly higher in the hypertensive group as compared to the normotensive group, $\mathrm{p}=0.001$ and $\mathrm{p}=0.004$, respectively. Significant number women who developed hypertension had unilateral $(46.2 \%)$ or bilateral $(20.4 \%)$ uterine artery diastolic notching, $\mathrm{p}=0.005$ and $\mathrm{p}=0.000$, respectively. Crude's odds ratio of uterine artery diastolic notching for prediction of hypertension in pregnancy was high, 9.894, 95\% CI, 3.273-29.907 as compared to vitamin D (<13.5 ng/ml) and hsCRP (>9.15 mg/L), 2.859, 95\% CI, 1.418-5.763 and 7.16, 95\% CI, 3.33-15.397.

Conclusions: Uterine artery diastolic notching in the early second trimester is found to be the best predictor of PE followed by first trimester hs-CRP and vitamin D.
\end{abstract}

Keywords: Gestational hypertension, hs-C reactive protein, Preeclampsia, Prediction, Uterine artery doppler, Vitamin D

\section{INTRODUCTION}

Gestational hypertension and preeclampsia (GHT/PE) complicate approximately $5-10 \%$ of pregnancies, incidence of it, in India is $8-10 \% .^{1,2}$ It is one of the leading causes of maternal and fetal complications. ${ }^{3}$ It also directly or indirectly contributes to a significant number of maternal deaths. ${ }^{4}$ Even with advancements in the obstetric care, it is not possible to accurately predict which women can develop this complication, in spite of 
being healthy in the first half of pregnancy. Starting low dose aspirin early in pregnancy can avert preeclampsia; therefore, it is important to find out women at risk of developing hypertensive disorders in pregnancy. ${ }^{5}$

Placenta in normal pregnancy produces a number of factors that are released into the maternal circulation. Alterations in the concentration of these factors in the maternal blood have been used to predict fetal outcome especially in terms of fetal anomalies and aneuploidy. Various authors have studied changes in the maternal serum concentration of these factors but the results so far have not been encouraging. Various other serum biomarkers in the early trimester have been studied to predict preeclampsia developing later in the pregnancy but till date no biomarker either single or in combination has been successfully able to predict the development of hypertension in low risk women. ${ }^{6}$

Normal levels of vitamin D are thought to play role in optimum placentation. Vitamin D has been suggested to mediate immune response at the feto-maternal interface and helps in increasing maternal immunological tolerance and reduces production of inflammatory mediators. ${ }^{7,8}$ Two meta-analysis have suggested possible role of low levels of vitamin D in development of PE., ${ }^{9,10}$

Development of preeclampsia is related to poor placentation and leads to increase in release of the markers of oxidative stress and inflammation from the placenta. hsCRP is one of the markers of systemic inflammation and it's levels are found to be high in women with PE. ${ }^{11,12}$ This biomarker has gained significance as it is easily available and is less costly as compared to other markers of inflammation.

Abnormalities in the placental implantation are also responsible for the high resistance flow in the uterine circulation. Hence, in women who develop hypertension later in pregnancy, there is failure of disappearance of uterine artery diastolic notching around midgestation. ${ }^{13-16}$ Previous studies have reported that combining biochemical markers of inflammation with uterine artery Doppler is more sensitive in predicting preeclampsia. ${ }^{17,18}$

The present study was planned to find out the association of first trimester maternal serum vitamin D and hs CRP levels, and second trimester uterine artery doppler with development of GHT and preeclampsia. It was also aimed to study prediction of subsequent development of GHT/PE by using these parameters.

\section{METHODS}

This was a prospective cross-sectional study conducted in the department of obstetrics and gynaecology in collaboration with department of clinical biochemistry and department of radiology, Vardhman Mahavir Medical College and Safdarjung Hospital, New Delhi. Before starting the study, permission was taken from the
Institutional ethical committee. All pregnant women attending antenatal clinic between October 2012 and June 2013, with 11 to 14 weeks gestational age, singleton pregnancy, willing to participate in the study and deliver at Safdarjung Hospital were recruited. Before starting the study, the procedure was explained to the women in a language understood by them and informed consent was taken.

A detailed history including history of the duration of sun exposure was taken and a complete physical examination including obstetrical examination was done at every visit to note maternal and foetal wellbeing. Besides, routine antenatal investigations, serum sample were taken for hsCRP and vitamin-D levels at 11-14 weeks. Serum hsCRP and vitamin-D levels estimation was done by enzyme linked immunosorbent assay (ELISA) technique.

Uterine artery colour doppler study was done between 22-24 weeks with colour doppler ultrasonography machine model Philips HD11 XE, Delhi by Philips Health Care. The probe was placed approximately two to three $\mathrm{cm}$ inside the iliac crests and the beam was directed downward and inward around $2 \mathrm{~cm}$ above the midpoint of inguinal ligament. Normally uterine arteries have strong forward diastolic flow due to low resistance in the uterine vessels. Diastolic notching seen on doppler flow study of uterine artery on one or both sides was noted.

Follow up of all women was done until delivery for the development of gestational hypertension and preeclampsia.

For the analysis of results, the study population was divided into 2 groups on the basis of subsequent development of hypertension. Hypertensive group comprised of women who subsequently developed gestational hypertension or preeclampsia and normotensive group comprised of women who remained normotensive till delivery. Gestational hypertension was defined as BP > 140/90 $\mathrm{mmHg}$ for the first time in pregnancy without proteinuria, after 20 weeks of gestation. Preeclampsia without severe features was defined as the presence of hypertension (BP $\geq 140 / 90$ $\mathrm{mmHg}$ ) with proteinuria on 2 occasions, at least 6 hours apart, but without evidence of end-organ damage, in a woman who was normotensive before 20 weeks' gestation. Severe preeclampsia was defined as the presence of 1 of the following symptoms or signs in the presence of preeclampsia: Systolic $\mathrm{BP} \geq 160 \mathrm{mmHg}$, Diastolic BP $\geq 110 \mathrm{mmHg}$ on 2 occasions with evidence of end organ damage. ${ }^{19}$

\section{Statistical analysis}

A master chart was created using MS-EXCEL. The descriptive statistics in term of mean, median, SD, range of all the parameters was calculated for hypertensive and for normotensive groups separately. SPSS 16 was used to analyse the data and Pearson Chi square test, t test, 
Fischer's test and Anova one-way were used to compare various parameters; $p$ value was kept $<0.05$ as cut off for significance. The receiver operating characteristic curve (ROC) curve was used to choose the cut off value of Vitamin D and hs-CRP. The logistic regression model was used for causal effect relationship. The effects of these predictors were measured in terms of Odds Ratio (OR) and its confidence intervals (C.I.).

\section{RESULTS}

A total of 153 women were included in the study, one woman was lost to follow up, therefore data of 152 women was analysed. The age and serum levels of vitamin D and hs-CRP in hypertensive and normotensive groups are shown in Table 1 .

Table 1: Distribution of study parameters in normotensive and hypertensive women.

\begin{tabular}{|llll|}
\hline Parameters & Normotensive $(\mathrm{N}=103)$ & GHT/PE $(\mathbf{N}=49)$ & p value \\
\hline Mean age \pm SD (years) & $24.47 \pm 3.64$ & $25.16 \pm 3.72$ & 0.474 \\
\hline Nulliparous & $44.1 \%$ & $71.3 \%$ & 0.530 \\
\hline Sun exposure $<30$ minutes & $22.11 \%$ & $22.45 \%$ & 0.996 \\
\hline Mean vitamin D (ng/ml) & $18.97 \pm 14.28$ & $12.28 \pm 7.08$ & 0.001 \\
\hline Mean hs-CRP $(\mathrm{mg} / \mathrm{l})$ & $8.39 \pm 7.39$ & $19.32 \pm 12.74$ & 0.004 \\
\hline Unilateral uterine artery diastolic notching & $4.8 \%$ & $46.2 \%$ & 0.005 \\
\hline Bilateral uterine artery diastolic notching & $0 \%$ & $20.4 \%$ & 0.000 \\
\hline
\end{tabular}

Table 2: Comparison of vitamin D, hs-CRP levels and uterine artery Doppler as predictors of P.E./GHTN.

\begin{tabular}{|lllllll|}
\hline Variable & $\begin{array}{l}\text { Sensitivity } \\
(\%)\end{array}$ & $\begin{array}{l}\text { Specificity } \\
(\%)\end{array}$ & $\begin{array}{l}\text { PPV } \\
(\%)\end{array}$ & $\begin{array}{l}\text { NPV } \\
(\%)\end{array}$ & $\begin{array}{l}\text { Accuracy } \\
(\%)\end{array}$ & $\begin{array}{l}\text { p } \\
\text { value }\end{array}$ \\
\hline Vitamin D $(<30 \mathrm{ng} / \mathrm{ml})$ & 98 & 10.6 & 34 & 91.7 & 38.6 & 0.067 \\
\hline Vitamin D $(<13.5 \mathrm{ng} / \mathrm{ml})$ & 61.2 & 64.44 & 44.8 & 77.9 & 63.4 & 0.003 \\
\hline hs-CRP $(>5 \mathrm{mg} / \mathrm{l})$ & 89.8 & 36.5 & 40 & 88.4 & 53.2 & 0.001 \\
\hline hs-CRP $(>9.15 \mathrm{mg} / \mathrm{l})$ & 73.5 & 72.12 & 55.4 & 85.2 & 72.5 & 0.000 \\
\hline UA Diastolic notching & 38.8 & 95.2 & 79.2 & 76.7 & 77.17 & 0.001 \\
\hline Vitamin D + hs-CRP $\square$ & 87.8 & 43.3 & 42.2 & 88.2 & 57.5 & 0.000 \\
\hline $\begin{array}{l}\text { Vitamin-D + hs-CRP } \square \\
\text { + Abnormal UA doppler }\end{array}$ & 34.7 & 95.2 & 77.3 & 75.6 & 75.8 & 0.000 \\
\hline
\end{tabular}

†positive predictive value $\$$ negative predictive value $\square$ serum vitamin $\mathrm{D}<30 \mathrm{mg} / \mathrm{ml}$ and serum hsCRP $>5 \mathrm{mg} / \mathrm{L}$.

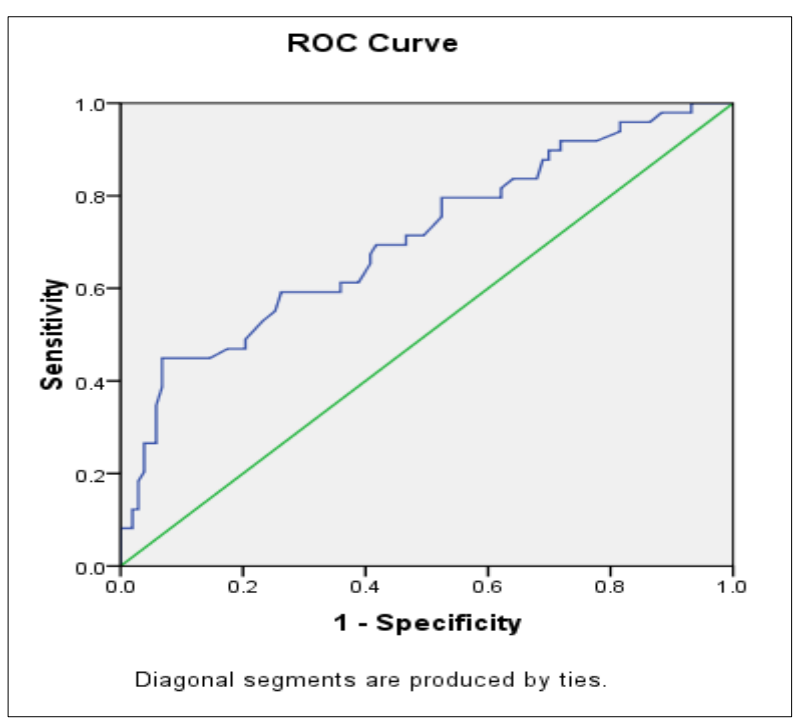

Figure 1: ROC curve of vitamin-D.

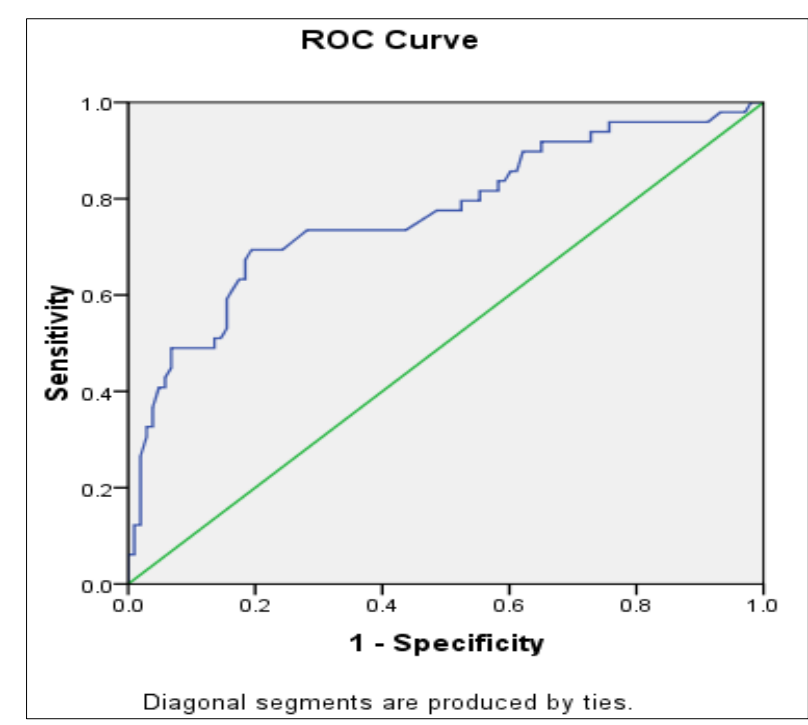

Figure 2: ROC curve of high-sensitive CRP. 
The mean vitamin D levels were significantly lower and mean hs-CRP levels were significantly higher in the hypertensive group as compared to the normotensive group, $\mathrm{p}=0.001$ and $\mathrm{p}=0.004$, respectively. Significant number women who developed hypertension had either unilateral or bilateral uterine artery diastolic notching, $\mathrm{p}=0.005$ and $\mathrm{p}=0.000$, respectively.

Serum vitamin-D and hs-CRP cut off levels of $13.5 \mathrm{ng} / \mathrm{ml}$ and $9.15 \mathrm{mg} / \mathrm{l}$, respectively were calculated from receiver operating characteristic curve (ROC Curve), Figure 1 and 2 . The comparison of sensitivity, specificity, positive predictive value and negative predictive value of serum vitamin D, hs-CRP and abnormal uterine artery Doppler done in early pregnancy was calculated for prediction of development of hypertension during pregnancy is shown in Table 2.

The sensitivity of hs-CRP was highest for prediction of hypertension during pregnancy whereas abnormal uterine artery doppler had highest positive predictive value. Crude's odds ratio of abnormal uterine artery for prediction of hypertension in pregnancy was high, 9.894, (95\% CI, 3.273-29.907) as compared to vitamin D and hs-CRP, Table 3.

Table 3: Crude odds ratio for maternal serum markers and uterine artery doppler for prediction of P.E./GHTN.

\begin{tabular}{|lllll|}
\hline Variable & Cut off & p value & OR & 95\% C.I. \\
\hline Vitamin-D (ng/ml) & 13.5 & 0.003 & 2.859 & $1.418-5.763$ \\
\hline Vitamin-D (ng/ml) & 30 & 0.112 & 4.667 & $0.584-37.305$ \\
\hline hs-CRP $(\mathrm{mg} / \mathrm{L})$ & 9.15 & 0.000 & 7.16 & $3.33-15.397$ \\
\hline hs-CRP $(\mathrm{mg} / \mathrm{L})$ & 5 & 0.005 & 4.011 & $1.458-11.033$ \\
\hline Diastolic notch & - & 0.000 & 9.894 & $3.273-29.907$ \\
\hline
\end{tabular}

\section{DISCUSSION}

Hypertensive disorders complicate $8-10 \%$ of the pregnancies and are responsible for $8 \%$ maternal mortality. ${ }^{3,4}$ The placental dysfunction associated with the pathology starts early in pregnancy. If we can identify women at risk of developing GHT/PE early in pregnancy, timely interventions can reduce maternal and fetal severe morbidity and mortality. Low levels of vitamin D, high levels of hsCRP which is a marker of inflammation along with early pregnancy uterine artery notching are associated with development of placental dysfunction and are hence been studied as markers for identifying women at risk of developing GHT/PE. The present study was planned to find out the association of first trimester vitamin D and hsCRP taking conventional and ROC cut offs and presence of second trimester uterine artery diastolic notching with risk of development of GHT/PE in women attending a tertiary care hospital.

The present study found the prevalence of GHT/PE to be $32.24 \%$ which is higher than reported by other authors. ${ }^{1,2}$

The higher prevalence of GHT/PE in the present study was because the study was conducted in a tertiary care hospital. There was no significant difference in the age and parity of women in the study and control group. Although there was no difference in the duration of sun exposure in women with and without GHT/PE, the vitamin D levels of women in the study group were lower than the control group, $\mathrm{P}=0.001$. The accuracy of predicting GHT/PE in women with hypovitaminosis D (< $30 \mathrm{ng} / \mathrm{ml}$ ) was $38.6 \%, \mathrm{P}=0.67$ but when the cut off was calculated from ROC, vitamin D levels of less than 13.5 $\mathrm{ng} / \mathrm{ml}$ were able to predict GHT/PE with accuracy of $63.4 \%, \mathrm{P}=0.003$, OR 2.859; 95\% CI 1.418-5.763.

Our findings are consistent with the reports of previous authors who also observed significantly lower levels of vitamin D in women who subsequently developed preeclampsia and significant correlation of vitamin D levels with maternal mean arterial pressure. ${ }^{20-22}$ A meta-analysis by Tabesh et al also showed significant association of vitamin D deficiency with risk of developing preeclampsia. $^{23}$

The mean first trimester serum hsCRP in the present study was found to be higher in the women who developed GHT/PE than the control group, 19.32 \pm 12.74 $\mathrm{mg} / \mathrm{L}$ and $8.39 \pm 7.39 \mathrm{mg} / \mathrm{L}$ respectively, $\mathrm{P}=0.004$. The hsCRP of $>5 \mathrm{mg} / \mathrm{L}$ were associated with predictive accuracy of $53.2 \%$ but with the value of $>9.15 \mathrm{mg} / \mathrm{L}$, calculated by ROC, the accuracy of prediction was $72.5 \%, \mathrm{P}<0.001$. The risk developing GHT/PE with first trimester hsCRP levels $>9.15 \mathrm{mg} / \mathrm{L}$ was significantly high, OR 7.16; 95\% CI-3.33-15.397, $\mathrm{p}=0.000$, risk calculated by taking the conventional cut-off of $<5 \mathrm{mg} / \mathrm{L}$ was also high OR 4.011, 95\% CI-1.458-11.033, $\mathrm{p}=0.005$.

Various studies have reported higher levels of serum hs CRP in the first trimester. ${ }^{11,24,25}$ A recent study by Elkady et al, also found higher first trimester hsCRP levels in women with preeclampsia as compared to the control group, $7.86 \pm 0.99$ and $2.71 \pm 1.69$, respectively, $\mathrm{p}<$ $0.001 .^{26}$ 
In the present study, the accuracy of uterine artery diastolic notch in predicting the development of GHT/PE was $77.17 \%, \mathrm{P}=0.001$, crude $\mathrm{OR}$ was 9.894 , 95\% CI3.273-29.90, $\mathrm{P}=0.000$. Kurdi et al, reported bilateral uterine artery diastolic notching in $12.4 \%$ of their cases and found OR of 12.8 for development of PE. ${ }^{27}$ Espinoza et al also found bilateral uterine artery notching to be associated with risk of developing PE later during pregnancy OR 2.1 ; 95\% CI 1.28-3.36, early onset PE OR 4.47; 95\% CI 1.50-13.35, and GHT OR 1.50; 95\% CI 1.02-2.26. They concluded that bilateral uterine artery diastolic notching between 23-25 weeks of gestation is an independent risk factor for the development of early onset $\mathrm{PE}$ and GHT. ${ }^{28}$

The main limitation of our study was that it was a hospital-based study done at a tertiary care centre; therefore, the incidence of GHT/PE in our study was high. Most of these women may be at high risk of development of hypertensive disorder during pregnancy and the results may not be applicable to the low risk women. Another limitation was that risk assessment of the participants on the basis of history was not done.

The main strength of our study is that we were able to follow most of the enrolled women till delivery; only one woman was lost to follow up. If a woman missed her scheduled visit, she was contacted telephonically and counseled to continue to be the part of study.

\section{CONCLUSION}

Early screening for risk of PE would benefit in identifying patients who are at high risk for maternal and perinatal complications due to GHT/PE developing later in the course of pregnancy. Uterine artery diastolic notching in the early second trimester is found to be the best predictor of PE. By taking ROC cut off hsCRP is better predictor for calculating risk of developing GHT/PE. However, taking conventional cut offs for hsCRP and vitamin D, combination of hsCRP and Vitamin D levels with uterine artery doppler are observed to yield better prediction of GHT/PE.

Funding: No funding sources Conflict of interest: None declared

Ethical approval: The study was approved by the Institutional Ethics Committee

\section{REFERENCES}

1. Dhall K, Dhall GI, Chugh KS, Dutta BN. A clinicopathological diagnosis of hypertensive disorders of pregnancy. Asia Oceania J Obstet Gynaecol. 1985;11(2):219-25.

2. Sajith M, Nimbargi V, Modi A, Sumariya R, Pawar A. Incidence of pregnancy induced hypertension and prescription pattern of antihypertensive drugs in pregnancy. IJPSR. 2014;5(4):163-70.
3. Sibai BM. Diagnosis and management of gestational hypertension and preeclampsia. Obstet Gynecol. 2003;102:181-92.

4. Jain K, Kavi V, Raghuveer CV, Sinha R. Placental pathology in pregnancy induced hypertension (PIH) with or without intrauterine growth retardation. Indian J Pathol Microbiol 2007;50(3):533-7.

5. Roberge $S$, Giguère $Y$, Villa $P$, Nicolaides $K$, Vainio $\mathrm{M}$, Forest JC, et al. Early administration of low-dose aspirin for the prevention of severe and mild preeclampsia: a systematic review and meta-analysis. Am J Perinatol. 2012;29(7):551-6.

6. Wu P, van den Berg C, Alfirevic Z, O'Brien S, Röthlisberger M, Baker PN, et al. Early pregnancy biomarkers in pre-eclampsia: a systematic review and meta-analysis. Int J Mol Sci. 2015;16(9):2303556.

7. Hyppönen E. Vitamin D for the prevention of preeclampsia? A hypothesis. Nutr Rev. 2005;63:22532.

8. Evans KN, Bulmer JN, Kilby MD, Hewison M. Vitamin D and placental-decidual function. J Soc Gynecol Invest. 2004;11:263-71.

9. Hyppönen E, Cavadino A, Williams D, Fraser A, Vereczkey A, Fraser WD, et al. Vitamin D and preeclampsia: original data, systematic review and meta-analysis. Ann Nutr Metab. 2013;63(4):331-40.

10. Tabesh M, Salehi-Abargouei A, Tabesh M, Esmaillzadeh A. Maternal vitamin D status and risk of pre-eclampsia: a systematic review and metaanalysis. J Clin Endocrinol Metab. 2013;98(8):316573.

11. Ghosh TK, Ghosh S, Bhattacharjee D. C-reactive protein levels in women with pregnancy induced hypertension. BJMS. 2011;10(3):159-62.

12. Timms PM, Mannan N, Hitman GA, Noonan K, Mills PG, Syndercombe-Court D, et al. Circulating MMP9, vitamin D and variation in the TIMP-1 response with VDR genotype: mechanisms for inflammatory damage in chronic disorders? QJM. 2002;95(12):787-96.

13. Hwang HS, Kwon JY, Kim MA, Park YW, Kim YH. Maternal serum hs-CRP in normal pregnancy in preeclampsia. Int J Gynaecol Obstet. 2007;98(2):105-9.

14. Wen SW, Huang L, Liston R, Heaman M, Baskett T, Rusen ID, et al. Severe maternal morbidity in Canada, 1991-2001. CMAJ. 2005;173(7):759-64.

15. Roberts JM, Cooper DW. Pathogenesis and genetics of pre-eclampsia. Lancet. 2001;357(9249):53-6.

16. Campbell S, Diaz-Recasens J, Griffin DR, CohenOverbeek TE, Pearce JM, Willson K et al. New Doppler technique for assessing uteroplacental blood flow. Lancet. 1983;26:675-7.

17. Costa FS, Murthi P, Keogh R, Woodrow N. Early screening for preeclampsia. Rev Bras Ginecol Obstet. 2011;33(11):367-75.

18. Thilaganathan B, Wormald B, Zanardini C, Sheldon J, Ralph E, Papageorghiou AT. Early-pregnancy multiple serum markers and second-trimester uterine 
artery doppler in predicting preeclampsia. Obstet Gynecol 2010;115(6):1233-8.

19. Cunnigham FG, Leveno KJ, Bloom SL, Hauth JC, Rouse DJ, Spong CY. Williams obstetrics $23^{\text {rd }}$ editions, New York. McGraw-Hill; 2010.

20. Bodnar LM, Catov JM, Simhan HN, Holick MF, Powers RW, Roberts JM. Maternal vitamin D deficiency increases the risk of preeclampsia. J Clin Endocrinol Metab. 2007;92:3517-22.

21. Baker AM, Haeri S, Camargo CA, Espinola JA, Stuebe AM. A nested case- control study of midgestation vitamin D deficiency and risk of severe preeclampsia. J Clin Endocrinol Metab. 2010;95:5105-9.

22. Hossain N, Khanani R, Hussain-Kanani F, Shah T, Arif S, Pal L. High prevalence of Vitamin-D in Pakistani mothers and their newborns. Int journal Gynae Obs. 2011;112:229-33.

23. Tabesh M, Salehi-Abargouei A, Tabesh M, Esmaillzadeh A. Maternal Vitamin D status and risk of pre-eclampsia: a systematic review and metaanalysis. J Clin Endocrinol Metab. 2013;98:3165-73.

24. Dhok AJ, Daf S, Mohod K, Kumar S. Role of early second trimester hs-CRP for prediction of adverse pregnancy outcome. J.K. Sci. 2011;13:141-4.

25. Nanda K, Sadanand G, Muralidhara Krishna CS, Mahadevappa KL. C-reactive protein as a predictive factor of preeclampsia. Int $\mathbf{J}$ Biol Med Res. 2012;3(1):1307-10.
26. Elkady OS, Kamel OI, Elmohsen WA, Badawy M. Role of The First Trimester maternal serum high sensitivity c-reactive protein and second trimester placental volume measurement by 3D doppler ultrasound in early detection of pre-eclampsia. EJHM. 2017;68(3):1442-51.

27. Kurdi W, Campbell S, Aquilina J, England P, Harrington K. The role of color Doppler imaging of the uterine arteries at 20 weeks' gestation in stratifying antenatal care. Ultrasound Obstet Gynecol. 1998;12:339-45.

28. Espinoza J, Kusanovic JP, Bahado-Singh R, Gervasi, MT, Romero R, Lee W, et al. Should bilateral uterine artery notching be used in the risk assessment for preeclampsia, small-for-gestational-age, and gestational hypertension. J Ultrasound Med. 2010;29(7):1103-15.

Cite this article as: Arora R, Salmani S, Bharti R, Kabi BC, Dabral A. First trimester serum vitamin D, hs-CRP and second trimester uterine artery diastolic notching in predicting gestational hypertension and preeclampsia. Int J Reprod Contracept Obstet Gynecol 2019;8:4897-902. 